\title{
AS INCIDÊNCIAS DAS REFLEXÕES DE JÜNGER NO CONCEITO DE TÉCNICA DE HEIDEGGER
}

\author{
EL IMPACTO DE LAS REFLEXIONES DE JÜNGER EN EL CONCEPTO DE TÉCNICA HEIDEGGER
}

Ricardo Cocco*

\begin{abstract}
RESUMO
Heidegger é o filósofo que nos permite compreender a técnica a partir da tese fundamental de que a técnica não é a mesma coisa que a essência da técnica e nos alerta para os perigos implicados no domínio técnico moderno. Para esta formulação do pensamento heideggeriano, a participação do pensamento de Ernest Jünger, como elaborador de diagnóstico de época, é crucial. Este artigo, de bases teóricas e de caráter bibliográfico, mostra como o pensamento de Heidegger acerca dessa temática apoiou-se de uma forma muito significativa e decisiva a partir de suas leituras e discussões com os escritos de Ernest Jünger. Heidegger, em relação à técnica moderna, posiciona-se menos numa discussão sobre novas tecnologias, ou lamentando o caráter alienador do trabalho industrial, mas sua crítica abrange todos os aspectos que contribuem para o esquecimento do ser. $\mathrm{O}$ autor não era inimigo da tecnologia, e nem via nela qualquer elemento demoníaco, mas acena para uma relação mais livre com ela a partir da compreensão de sua essência.
\end{abstract}

PALAVRAS-CHAVE: Filosofia. Heidegger. Técnica. Jünger. Gestell.

\section{RESUMEN}

Heidegger es el filósofo que nos permite comprender la técnica desde la tesis fundamental de que la técnica no es lo mismo que la esencia de la técnica (HEIDEGGER, 1997) y nos advierte de los peligros que implica la técnica moderna. Para esta formulación del pensamiento heideggeriano, la participación del pensamiento de Ernest Jünger, como escritor de diagnóstico de la época, es crucial. El artículo, basado en el carácter teórico y bibliográfico, muestra cómo el pensamiento de Heidegger sobre la técnica moderna se basó de manera muy significativa y decisiva a partir de sus lecturas y discusiones con los escritos de Ernest Jünger (2000, 2002). Heidegger, en relación con la técnica moderna, se posiciona mucho menos en una discusión sobre nuevas tecnologías o lamentando el carácter alienante del trabajo industrial, pero su crítica abarca todos los aspectos que contribuyen al olvido del ser. El autor no era enemigo de la tecnología, ni vio en ella ningún elemento demoníaco, pero hace un llamado para una relación más libre con ella desde la comprensión de su esencia.

PALAVRAS-CLAVE: Filosofia. Heidegger. Técnica. Jünger. Gestell.

\footnotetext{
* Doutorado em Educação no PPGEDU da Universidade de Passo Fundo - UPF. Mestrado em Filosofia pela Universidade do Vale do Rio dos Sinos (2007). Exerce atividade de técnico em assuntos educacionais na Universidade Federal de Santa Maria (Campus Frederico Westphalen). E-mail: ricardo.cocco@ufsm.br.
} 


\section{INTRODUÇÃO}

A convicção profundamente arraigada no âmago da consciência moderna de que a modernidade (a era da técnica) é a era do progresso deixa a impressão de que o homem pode, facilmente, manipulá-la. Mas acontece o contrário: ele é manipulado por aquilo que cada vez mais tenta controlar.

Martin Heidegger, após a "Kehre", traduzida como a viravolta" na qual se inscreve a sua filosofia a partir da segunda metade dos anos 30, propõe-se, no texto intitulado "Die Frage nach der Technik" (A questão da técnica) proferido a 18 de novembro de 1953, na Escola Superior Técnica de Munique, uma reflexão acerca da técnica moderna, enfatizando a ligação entre o pensamento da subjetividade - que marca a cultura ocidental - e o triunfo da técnica moderna no plano da civilização, e como essa relação se inscreve na história da metafísica, ligando-a com sua tese do esquecimento do ser. Heidegger desabriga-nos de nossas concepções mais correntes acerca da técnica e da tecnologia moderna. Desconstrói nossos conceitos convencionais, visando questionar nossas pseudocertezas no intuito de fazer manifestar livremente a sua essência e fundamento.

Heidegger, em relação à técnica moderna, posiciona-se menos numa discussão sobre novas tecnologias, ou lamentando o caráter alienador do trabalho industrial, mas sua crítica abrange todos os aspectos que contribuem para o que ele denomina esquecimento do ser. $\mathrm{O}$ chamado segundo Heidegger ${ }^{2}$, marcado por uma profunda decepção política, aproxima-se e distancia-se da sociedade. Distancia-se de forma prática: depois da sua gestão de dez meses

\footnotetext{
${ }^{1}$ Viravolta é o nome que recebeu a mudança no pensamento de Heidegger a partir dos anos 30. Conforme Stein (2001, p. 300-302), "o nome (viravolta), que surgiu por referência de Heidegger, deveu sua oficialização, talvez, pelo fato de ter se tornado uma designação que atinge o essencial de seu pensamento. O primeiro elemento que pode chamar atenção para esse movimento de viravolta foi o fato de que a partir de 1929 Heidegger não vai falar mais, explicitamente, em suas lições, em fenomenologia, como o vinha fazendo. Suas análises diretas de autores da tradição filosófica ocidental e de poetas pareciam encaminhá-lo para outra direção. Em seu lugar se impõe a introdução de novos modos de falar. As palavras-chave de Ser e tempo tomam sentidos mais amplos. Há uma insistência crescente nos gregos, e o pensamento de Nietzsche aparece em evidência nas discussões de Heidegger. A analítica existencial como caminho da interrogação pelo sentido do ser parece ficar para trás, e parecem ser necessários novos caminhos para o ser".

${ }^{2}$ A distinção do "primeiro" e do "segundo" Heidegger é feita por ele na Carta ao Pe. Willian Richardson em Philosophisches Jahrbuch, Freiburg/München, 1965 (HEIDEGGER, 2004b, p. 49-62). Heidegger admite a distinção entre o pensamento do Heidegger I (antes) e o Heidegger II (depois da viravolta), mas com uma ressalva: "Sua distinção entre o 'Heidegger I' e 'Heidegger II' somente se justifica sob a condição de, constantemente, se atentar: somente a partir do que é pensado sob o I torna-se acessível, em primeiro lugar, o que deve ser pensado sob o II. Mas o I somente se torna possível se vem contido no II". Essa discussão está presente também em Stein (2001, p. 297-391).
} 
como reitor da universidade de Freiburg (1933/34) nunca mais assume - até a sua morte em 1976 - uma função pública ou administrativa, nem faz declarações sobre temas políticos, o que inclui o silêncio sobre sua relação com o movimento nacional-socialista. Mas o filósofo aproxima-se da realidade tentando compreendê-la, não em termos sociais, senão em termos ontológicos.

Este artigo apresenta o pensamento de Heidegger acerca da técnica moderna, e como sua compreensão desse tema apoiou-se de uma forma muito significativa e decisiva a partir de suas leituras e discussões com os escritos de Ernest Jünger. As análises de Jünger sobre a técnica e a ciência moderna expressam o humor de uma época. Elas, explicitadas à luz do conceito de vontade de poder (lugar, segundo ele, do ser em nossa época) de Nietzsche, colaboraram para que Heidegger viesse a perceber a insuficiência da sua hermenêutica da facticidade de Ser e tempo, incapaz então de compreender o sentido da época moderna.

\section{A QUESTÃO DA TÉCNICA EM HEIDEGGER}

Heidegger é o filósofo que nos permite compreender a técnica a partir da tese fundamental de que "a técnica não é a mesma coisa que a essência da técnica", (HEIDEGGER, 1997, p. 41) e que nos alerta para os perigos implicados na técnica moderna. No texto A questão da técnica, de 1953 (HEIDEGGER, 1997), o autor parte da compreensão de que a técnica não é a mesma coisa que a sua essência e de que esta, de modo algum, é algo técnico.

Heidegger nunca admitiu que o considerassem um adversário da técnica. Dizia nunca ter falado contra nem ter denunciado seu caráter demoníaco. Afirmava querer compreender apenas sua essência. Do mesmo modo, não responsabilizava o homem pela hegemonia da técnica, nem acreditava na eficácia das lamentações contra os avanços dela. "A concepção corrente da técnica de ser ela um meio e uma atividade humana pode chamar-se a determinação instrumental ou antropológica da técnica” (HEIDEGGER, 1997, p. 43). Para ele, as máquinas ou aparelhos tecnológicos são apenas saliências da técnica moderna. A compreensão desta não se reduz à manipulação da técnica de maneira devida. A técnica, em sua essência, não se refere a máquinas, técnicas complexas ou mesmo fabricação de objetos e artefatos. Esses, na verdade, são os produtos de um mundo tecnicamente orientado, mas não 
são, porém, o fundamento do mundo. Permaneceremos afastados de sua essência enquanto concebermos e lidarmos apenas com o que é técnico, e enquanto a ele nos moldarmos ou dele nos afastarmos.

O autor de Ser e tempo recusa a tese de que a técnica é, em si, eticamente neutra, residindo os problemas na sua boa ou má utilização ou aplicação. Então, propõe-se a questionar a técnica com a expectativa de preparar uma relação mais livre para com ela, abrindo o nosso Dasein $^{3}$ para a sua essência.

\begin{abstract}
Quando procuramos a essência de uma árvore, devemos estar atentos para perceber que o que domina toda a árvore não é propriamente uma árvore, possível de ser encontrada entre outras árvores. Assim, pois, a essência da técnica não é de modo algum algo técnico. E por isso nunca experimentaremos nossa relação com a sua essência enquanto somente representarmos e propagarmos o que é técnico, satisfizermo-nos com a técnica ou escaparmos dela. (HEIDEGGER, 1997, p. 43).
\end{abstract}

Perguntar pela essência é perguntar pelo que tal coisa é. Heidegger pensa a essência em sua forma verbal, como um essencializar. Nessa perspectiva, ele "escapa" da concepção neutral da técnica reduzida ao mero conjunto de meios para se alcançar determinados fins, como se o seu estatuto dependesse única e exclusivamente de seu bom ou mau uso. A definição da técnica não pode ser um ponto de chegada; antes, ela constitui um ponto de partida para uma interrogação rumo a uma compreensão. Portanto, o autor não visualiza uma solução final do problema da técnica a partir do seu completo domínio, mas acena para uma relação mais livre com ela a partir da compreensão de sua essência. Nesse horizonte, ele desconstrói o conceito grego de techne $e^{4}$, mostrando que a origem da técnica está na maneira como nos defrontamos com a natureza. Assim, compreendemos que a essência dessa atitude (técnica) não participa ela também do caráter operativo dessa atitude.

\footnotetext{
${ }^{3} \mathrm{O}$ "aí" $(D a)$ é o espaço que abre e ilumina, é a possibilidade, a condição de ser. Dasein unifica o homem, evitando a tradicional tripartição corpo, alma e espírito. É a existência. Nomear o existente humano como Dasein implica uma neutralização da possibilidade da analítica ser tomada como uma investigação antropológica ou como humanismo. Não cabe perguntar "o que" ele é, deveríamos perguntar "quem" ele é, e a resposta dependerá de, e até mesmo consistirá na, decisão de Dasein: pode ser eu mesmo ou pode ser o ninguém a quem todo Dasein já se rendeu ao ser em meio aos outros. Dasein não é o homem, mas um relacionamento com o ser que o homem adquire e que pode perder.

${ }^{4} \mathrm{~A}$ experiência grega da techne consistia numa revelação daquilo que permanece como potencial, da mesma forma como se entende que a escultura poderá estar escondida na pedra por esculpir. Como consequência, techne era uma forma de 'cuidar', um modo de incutir os contornos, formas e funções potenciais dos seres. Heidegger acredita que esta indução evidencia uma abertura resoluta para os seres na procura de fundamentar os seres nos próprios termos (THIELE, 1995, p. 255).
} 
Heidegger observa que a raiz da palavra técnica é techne, que significa revelação de algo, não tanto o fazer de algo, mas seu desvendar, ou trazer à luz. Techne denota o movimento dos seres que provêm do oculto para a revelação específica da sua aparência; nunca designa a ação de fazer. Nessa leitura, a techne nunca seria uma atividade do homem, mas uma produção (poiesis) que deixa de antemão que o ente chegue à manifestação de acordo com seu aspecto.

De acordo com a reflexão heideggeriana, a técnica moderna é também um desvelamento. No entanto, o que impera e domina a técnica moderna é um desafiar como uma maneira de expor (Entbergen), que tem características de dispor (Stellen), no sentido de provocação (Herausfordern). Um desvelamento provocante que impõe à natureza a obrigação de fornecer energia, capaz de, como tal, ser beneficiada, armazenada e reutilizada constantemente. "Um desafiar que estabelece, para a natureza, a exigência de fornecer energia susceptível de ser extraída e armazenada enquanto tal.” (HEIDEGGER, 1997, p. 57). A natureza não é mais objeto, mas fundo invisível e inesgotável à disposição, que se desvenda, enquanto tal, sob o impacto do encomendar. A técnica moderna não se conjuga mais à natureza, mas arranca da natureza as condições de sua própria perpetuação, ao custo de uma contínua agressão.

O desencobrimento/desvelamento característico da técnica moderna não se desenvolve numa produção no sentido de poiesis ${ }^{5}$, mas o desencobrimento que domina a técnica moderna, segundo Heidegger, traduz-se num sentido de provocação (Herausfordern). Essa provocação consiste numa espécie de intervenção que se dirige à natureza em vista de um processo de acumulação de energia que se extrai. A técnica moderna provoca a natureza, e ela é obrigada a responder de acordo com a provocação. Se a técnica moderna é um desvelamento do ser, ela o é a partir de um modo provocativo, é um desvelamento/desencobrimento provocante ${ }^{6}$.

\footnotetext{
${ }^{5}$ A poiesis é a abertura que acolhe (HEIDEGGER, 1997, p. 53). Acolher significa aguardar atentamente e serenamente, oportunizando clareira para o revelar a partir do acontecer próprio do ser. A poiesis não é um simples fabricar por meio da correta aplicação de meios e habilidades a fim de arrolar o ente ou de modelar a physis (natureza), mas é o caminho que conduz o ente à sua própria aparição. Michelangelo disse certa vez que a escultura já existia na pedra, bastava libertá-la. É mais ou menos assim que se deve imaginar o que Heidegger quer dizer com produzir e deixar acontecer (SAFRANSKI, 2000, p. 463).

6"A técnica moderna não se satisfaz simplesmente em trazer os entes à presença, mas os descobre já enquanto matéria ou recurso que podem ser continuamente reutilizados, transformados, economizados e manipulados em um ciclo supostamente infinito no qual se instala a devastação da natureza, fixada agora como simples fonte de energias disponíveis. [...] $\mathrm{O}$ que se desvela pela tecnologia moderna presta-se à sua contínua manipulação, controle, direcionamento, conservação e exploração, mantendo-se sempre disponível e a postos para ser renovadamente utilizado." (DUARTE, 2001, p. 43 e 45).
} 
A diferença entre os dois modos da técnica é ilustrada por Heidegger na comparação de um velho moinho movido a vento com a extração de carvão e minerais; do cultivo do campo pelo camponês tradicional com a agricultura industrial. Ou mesmo no exemplo do rio Reno.

\begin{abstract}
Instala-se uma central elétrica no rio Reno, ela intima o rio a fornecer sua pressão hidráulica, as turbinas giram, cujo girar faz funcionar aquelas máquinas que geram energia elétrica, para a qual estão preparadas as centrais interurbanas e sua rede de energia destinada à transmissão de energia. No âmbito dessas consequências engrenadas de encomenda de energia elétrica aparece também o rio Reno como algo encomendado. A central hidroelétrica não está construída no rio Reno como a antiga ponte de madeira, que há séculos une uma margem à outra. A situação se inverteu. Agora é o rio que está construído na central elétrica. O rio que o Reno é hoje, a saber, fornecedor de pressão hidráulica, o é pela essência da usina. (HEIDEGGER, 1997, p. 59).
\end{abstract}

O rio Reno, no caso, surge como algo a nosso serviço. A técnica moderna intima e provoca a natureza a fornecer sua energia e a deixá-la disponível. Ela é um desvelar que desafia e que põe (Stellt) a natureza como simples fonte de recursos disponíveis a serem continuamente encomendados (Bestellt). Enquanto desvelamento é interpelação provocante, faz aparecer a natureza como fundo de reserva (Bestand), como algo que responde à encomenda, como fundo.

A técnica moderna revela o mundo como um desafio que extrai aquilo que permanece em potencial com vistas a utilizá-lo. Esse desvelamento que expõe tudo como reserva disponível reduz, rumo à eficiência, a Terra e todas as criaturas a estatuto de matéria-prima. $\mathrm{O}$ mundo todo é, tecnologicamente, concebido como reserva, e permanece aguardando pela sua utilização, no modo como aguarda seu ser que será utilizado de forma mais eficiente.

A origem da técnica reside no modo como nos defrontamos com a physis ${ }^{7}$, se a deixamos acontecer por si ou se a provocamos. Assim, Heidegger ultrapassa a concepção instrumental da técnica e a discussão que mantém a questão da técnica atrelada ao bom ou mau uso que dela se faz. Para ele, a descoberta da natureza como reservatório não depende da decisão voluntária do Dasein e nem se esclarece por meio de uma análise de seu ser próprio.

A técnica não é um simples fazer humano, "não se reduz a um mero fazer humano, mas se mostra como um desafio que põe o homem a dispor do real como disponibilidade"

\footnotetext{
${ }^{7} \mathrm{O}$ conceito de physis é mais original que a palavra natureza em seu sentido moderno e tardio. Ele abarca tanto a natureza quanto a história.
}

Sapere aude - Belo Horizonte, v. 10 - n. 20, p. 613-633, Jul./Dez. 2019 - ISSN: 2177-6342 
(HEIDEGGER, 1997, p 65). O homem é movido por uma provocação e colocado na posição do desocultar a efetividade à maneira do fundo que encomenda.

A técnica moderna dirige para a natureza uma provocação na qual ela é convocada em vista de que se anuncie de alguma forma comprovável por cálculo e permaneça à nossa disposição. A essência da técnica é o que o Filósofo chama de Gestell ${ }^{8}$ : uma interpelação produtora que põe o homem a desvelar o real como fundo de reserva no modo do encomendar, assim permanecendo condenado à vontade do cultivo do que é calculável em sua facticidade.

O Gestell é o sujeito no ato de provocar. Consiste em pôr o homem a desvendar o real como fundo no modo do encomendar. O homem está impotentemente entregue à essência da técnica. Esse dispositivo tornou-se o nosso destino (geschick) enquanto envio que põe no caminho, enquanto junção daquilo que está "posto" (stellt) pelo sujeito tecnológico. Significa postular que todas as coisas são basicamente a mesma: matéria-prima. Esse é o momento em que os entes são descobertos enquanto materiais/recursos a serem utilizados e postos como fonte de suprimento de energias. "O homem sofre o controle, a exigência e a injunção de um poder que se manifesta na essência da técnica e que ele próprio não domina" (HEIDEGGER, 1969, p. 9). Várias são as opções utilizadas para apresentar a noção de Gestell. Aqui apresentamos algumas. Conforme tradução de Marco Aurélio Werle, Gestell é "invocação desafiadora que reúne o homem a requerer o que se descobre enquanto a subsistência" (HEIDEGGER, 1997, p. 65). Como "armação" ou "com-posição", segundo a tradução de Emanuel Carneiro Leão: “o apelo de exploração que reúne a dispor do que se desencobre como disponibilidade" (HEIDEGGER, 2001, p. 23), ou como "interpelação produtora"

\footnotetext{
${ }^{8}$ Gestell como andaime, estante, esqueleto; ge: o que congrega; stellen: pôr em pé, não como algo estático, mas animado, esqueleto que não está morto. Heidegger propõe um novo sentido para a técnica, mantendo a maleabilidade do conceito. Gestell significa a reunião daquele pôr que desafia o homem a desencobrir a realidade no modo do requerer como disponibilidade. Significa o modo do desencobrimento que impera na essência da técnica moderna e não é propriamente nada de técnico. Ao que é técnico, em contrapartida, tudo o que conhecemos como estruturas, hastes, suportes, e que são peças do que se denomina como sendo uma montagem. Esta, contudo, com todo o seu conjunto de peças, recai no âmbito do trabalho técnico, que sempre corresponde ao desafio da Gestell, mas nunca a perfaz ou mesmo a efetua (HEIDEGGER, 1969, p. 67). Entre os conceitos certamente intraduzíveis de Heidegger encontra-se o Gestell. O verbo stellen (comumente: pôr; em Heidegger: colocar algo, dispor, num ato de imposição, numa posição para atender uma demanda específica; demandar). O Ge-stell faz parte dessa nuvem de conceitos, além do mais, é de certa maneira a essência do desocultamento técnico, então de todas as atividades modernas, que deixam se caracterizar como stellen, isto é, como um certo acesso ao ser, que o demanda e o desafia. No ato da imposição (Durchsetzen) da disposição (das Stellen) desoculta a técnica moderna o ser, todavia de uma maneira que impossibilita a sua revelação plena. A técnica é, entendida assim, uma forma do esquecimento do ser.
} 
sugerido por Stein na tradução da Carta-resposta de Heidegger ao professor da Universidade de Tóquio, Dr. Takehiko Kojima, de 1965 (HEIDEGGER, 2002, p. 195).

O que está em questão não é o desenvolvimento de qualquer máquina ou artefato, os quais, para Heidegger, são meros sintomas desse impulso tecnológico globalizante expansivo do Gestell como essência da técnica. O Gestell não constitui nada de tecnológico no sentido de não estar fundamentado na produção de máquinas (a sua consequência mais visível), mas na revelação ontológica do ser do ente enquanto reserva.

A essência da técnica determina-se como um modo do dar-se do ser e que não se limita a uma atividade humana, mas como um meio do desocultar os entes como reserva disponível ${ }^{9}$.

Para esta formulação do pensamento heideggeriano, este artigo pretende mostrar o quanto a participação do pensamento de Ernest Jünger, como elaborador de diagnóstico sobre a época, é crucial. Para isso, dentre os trabalhos de Jünger, será discutido especialmente o texto Mobilização total (JÜNGER, 2002) e o Der Arbeiter (JÜNGER, 2000). Esses textos fornecem a Heidegger uma clara exposição sobre a condição metafísica do Ocidente no tempo do fim da história da própria metafísica. Heidegger percebe, na compreensão de Jünger a respeito do desamparo total do soldado-trabalhador numa situação extrema de combate, uma experiência autenticamente metafísica. É também por ele que Heidegger compreende que a técnica moderna é uma mera manifestação empírica de um escondido poder que está transformando o mundo e do qual a política reinante pouco sabe. Jünger concebeu a técnica moderna como a última manifestação da eterna - mas escondida - vontade de poder, o que abriu os olhos de Heidegger para a importância da leitura de Nietzsche, que já apregoava que uma época viria em que seria buscado o domínio da Terra, e por ele lutariam os homens entre si, e esse domínio dar-se-ia através de meios tecnológicos.

Essa vontade de poder, conceito cunhado por Nietzsche, estava mobilizando o planeta para um delírio tecnológico. A expressão da misteriosa e compulsória exigência a que a vida nos subjuga Jünger chama de mobilização total (em texto de mesmo nome de 1930). Esse conceito serve para descrever o processo globalizante da técnica moderna. Essa mobilização

\footnotetext{
9 “A natureza, que antecede a operação técnica, é tomada como fundo disponível para o cálculo de tudo. [...] Esse cálculo domina pura e simplesmente a vontade, [...] este cálculo absoluto e incondicionado feito com os termos 'provocação' (Herausforderung) e 'composição' (Gestell) é a inversão da prioridade ontológica dos gregos. A técnica não se regula mais a partir das possibilidades pré-dadas da natureza. Pelo contrário, é ela que ocupa a função de regular o poder da natureza a partir da construção do projeto, [...] no planejamento de uma requisição generalizada no sentido de exploração." (FLEIG, 2005, p. 85).
} 
esculpe um novo tipo de humanidade compelida pela Gestalt do trabalhador. A essência da técnica moderna nada tinha de técnica, ao contrário, a sua essência consistiria, antes, no fato de a humanidade ter sido acorrentada por uma vontade irresistível de dominar, que a si mesma exprimia sob a aparência de uma máquina tecnológica. "Para possuir uma relação real com a técnica, é preciso ser mais do que técnico.” (JÜNGER apud HEIDEGGER, 1969, p. 29).

Para Heidegger, a mobilização total de Jünger é uma forma de manifestação do mesmo impulso vigorante da racionalidade científica moderna, por meio da qual se processa a integração sistemática da totalidade do ente no quadro objetivante de um representar operatório, que perpassa e fundamenta a apropriação da natureza (e da natureza humana) pela racionalidade tecnológica.

Heidegger esteve sempre, em suas obras, de alguma forma preocupado com o fenômeno da técnica e da ciência moderna. Essa preocupação assume contornos mais claros a partir do interesse pela vinculação entre as questões da existência fática e os problemas concernentes à história da metafísica, inclusive em Ser e tempo. Ele percebe que há uma relação intrínseca entre o declínio do Ocidente em direção ao niilismo e o declínio da compreensão da humanidade relativamente ao ser. No entanto, o risco de que suas ideias nos anos 20 pudessem ser deixadas na penumbra em virtude da insuficiência do projeto de repensar o sentido do ser a partir da ontologia fundamental fez com que o Filósofo concentrasse sua atenção sobre a questão da técnica moderna, buscando um novo horizonte para ela. Essa mudança de perspectiva foi potencializada a partir de dois fatos: primeiro, a sua proximidade com o nacional-socialismo; e, segundo, o seu contato e interpretações dos escritos de Ernest Jünger, principalmente nos textos A mobilização total (Die totale Mobilmachung) de 1930 e $O$ trabalhador (Der Arbeiter) de 1932, e discordância relativamente às previsões de Jünger sobre o futuro tecnológico.

\section{JÜNGER E A EXPERIÊNCIA DA GUERRA MODERNA COMO FENÔMENO ESTÉTICO}

Ernest Jünger, nascido em Hanôver em 1895, jovem aventureiro, juntou-se aos dezesseis anos à Legião Estrangeira Francesa. Enfadado com os constrangimentos e limitações da Alemanha dos anos de 1910, viu, no eclodir da Primeira Guerra Mundial, uma possibilidade de libertação do tédio da vida do dia a dia numa sociedade extremamente rígida. 
Foi soldado voluntário da infantaria no início dos combates, mas, por sua bravura, foi elevado, logo cedo, ao posto de comandante das tropas. Ferido quatorze vezes, foi um dos mais condecorados heróis alemães.

O seu primeiro livro, intitulado Tempestade de aço, narra as experiências vividas por ele nas trincheiras da Primeira Guerra. Embora inicialmente entusiasmado e com um fervor nacionalista exaltado, os soldados, e Jünger como voluntário, entraram em contato com a terrível realidade do caráter implacável e horrífico da Guerra de Trincheiras. Desde esses primeiros escritos, já se percebe a tentativa de Jünger de compreender e justificar os horrores da guerra. E ele o faz a partir da tese de que a guerra não passa de um fenômeno estético que tudo arrasta, "como um espetáculo cativante com múltiplas transformações e velamentos que a pura configuração (Gestalt) ${ }^{10}$ da guerra sofre com o passar de tempos e espaços humanos" (JÜNGER, 2002, p. 189).

O horrível torna-se emocionante, e os acontecimentos espantosos mudam de sentido e conotação pelo espetáculo obsessivamente belo que simboliza a vontade incondicional de domínio em ação por trás de tudo. Nesse sentido, para Jünger, a guerra pode ser explicada por seu viés estético, em que a arte pode tornar o horror uma noção aceitável, o sublime transformar-se no artístico domesticar do horrível, e o cômico passar a ser a descarga artística da náusea do absurdo.

Assim, os participantes da guerra passam a ser, em vez de aliados ou inimigos, companheiros mobilizados de uma mesma aventura. "O chefe do batalhão já não mais conhece a diferença entre combatentes e não combatentes.” (JÜNGER, 2002, p. 198). Jünger via a guerra como uma tempestade de aço, transformada num processo de trabalho gigantesco que envolve produção e consumo constantes. Junto ao campo de batalha, emergem uma indústria de abastecimento, a indústria de armas, e um exército de trabalhadores em geral. Esse fenômeno exige uma mobilização total que abrange até a criança em seu berço. Dessa forma, o soldado, o trabalhador e tudo o mais estão em função de algo que é maior do que a soma de seus elementos juntos, e de tal forma organizados com a finalidade de transformar o planeta num prodígio tecnológico totalmente administrado. Para referir-se a esse processo globalizante da tecnologia moderna, Jünger (2002, p. 193) cunhou a expressão "mobilização total".

\footnotetext{
${ }^{10} \mathrm{O}$ texto referido traduz o conceito de Gestalt, largamente utilizado por Jünger, por configuração (forma, feitio, figura, modelo). Configuração como um todo que abrange mais do que a soma de suas partes.
} 
A experiência de Jünger fez com que, em seus escritos, a guerra fosse elevada como o fenômeno mais perceptível de um poder superior de mobilização contra o qual a humanidade era impotente. No campo de batalha, ele sentiu-se como se fosse uma mera peça dentro de um enorme processo tecnológico. Ou aprendia a participar da ordem tecnológica de boa vontade ou pereceria. Devemos ressaltar que Jünger lia os acontecimentos numa perspectiva estética, e não moral ou política. Em vista disso, para ele, não haveria domínio da vida que não fosse, também, considerado material para a arte, inclusive para a vontade que concebe o planeta como o seu material básico. Jünger representava o gigantesco processo da tecnologia moderna como um fenômeno estético, um terrível, mas sublime espetáculo que estava "para além do bem e do mal". Ele interpretava a questão da guerra e da tecnologia através do viés de categorias estético-literárias, e propunha uma explicação para a realidade socioeconômica a partir de símbolos míticos de um poder "sobrenatural" e irracional. Essa mitologia de Jünger concebia, também, a história como um fenômeno simbólico e estético, um espetáculo configurado pela estrutura fundamental dirigente, uma fonte insuperável e não racional que molda a realidade histórica. A experiência da guerra possibilitou a ele uma perspectiva quase mágica sobre a estrutura fundamental escondida que governaria a história. A experiência estética, segundo ele, tornava possível uma pessoa encontrar a dimensão da eterna vontade de poder que age em todas as coisas.

Jünger concebe a guerra como a mais perigosa forma de trabalho, o soldado como o modelo de trabalhador moderno, e a batalha do equipamento como visão autêntica dos tempos modernos. Esse novo modelo de combatente-trabalhador, cunhado pela Gestalt tecnológica, abraça a tecnologia e faz de tudo para a materialização do imperativo categórico do domínio. A Gestalt é a expressão da misteriosa exigência que a vida nos impõe. Ela compele a humanidade ao dilema de render-se ou ser destruída. Assim, podemos perceber que, para Jünger, a arte da guerra fazia avançar a Gestalt tecnológica do planeta, aproximando, e muito, as figuras do soldado e do trabalhador, convertendo-os simplesmente em operários em função dessa intenção expansionista, que é movida por uma vontade que deseja somente a sua própria expansão.

A compreensão de Jünger acerca do progresso segue a mesma linha de raciocínio quando ele diz que "o gênio da guerra conseguiu atingir e permear o espírito do progresso" (JÜNGER, 2002, p. 190). Essa constatação introduz uma nova compreensão de progresso que 
até então era "a grande igreja do povo a partir do século XIX, a única que pôde gozar de autoridade efetiva e crença acrítica" (p. 192). Ele afirma que o "progresso não é progresso algum" (p. 191), mas que ele tem suas origens na crença ilusória nas capacidades humanas de conduzir a história, visto que ele concebe a história como a manifestação de forças mais fortes que as meramente humanas. Submetido a essas forças, o trabalhador desenvolve símbolos de culto à tecnologia. "Porém, mais importante que essa constatação é, talvez, perguntar se não é mais secreto e de outro tipo o próprio significado do progresso, o qual se serve de um esconderijo privilegiado: a máscara da aparentemente tão translúcida razão” (p. 191). Essa crença no progresso impede uma compreensão mais apurada da essência da tecnologia que existiria escondida por debaixo da superfície material dos acontecimentos. Para Jünger, portanto, a essência da tecnologia moderna nada tinha de técnico, pelo contrário, o essencial consistiria no fato de a humanidade ter sido acorrentada por uma vontade irresistível de dominar, que a si mesma exprimia-se sob a aparência de máquina tecnológica.

\section{O CONCEITO DE GESTALT DO TRABALHADOR E A MOBILIZAÇÃO TOTAL}

O conceito de Gestalt é central na compreensão de Jünger acerca da técnica moderna, e o conceito heideggeriano de técnica moderna deve muito a essas reflexões. Segundo Jünger, a Gestalt mobiliza o planeta em direção a um delírio tecnológico, em que o progresso prepara avanços que seriam considerados impensáveis. No entanto, as transformações e os avanços tecnológicos não seriam nada mais do que manifestações empíricas de um poder escondido que está a transformar o mundo. Há aqui uma referência explícita ao que Nietzsche chama de vontade de poder, a qual apela à humanidade que domine a terra através de meios tecnológicos. Essa humanidade é empurrada pela Gestalt do trabalhador a produzir, incessantemente, cada vez mais poderosos inventos tecnológicos a serviço dessa dominação técnica. A humanidade moderna é moldada por essa concreta, energética, original e criativa força que organiza toda a experiência humana em termos de participação no trabalho.

A técnica moderna para Jünger é a última manifestação da eterna, mas escondida, vontade de poder, sendo que a grande indústria e o equipamento mecânico de guerra nada mais são do que irrupções empíricas de algo que transcende o domínio causal-material.

Essa configuração de forças como um todo, que a tudo abrange, é a realidade mais profunda e mais plena de significações que o próprio homem; é o poder que age através dele, 
e que age como se ele fosse uma espécie de fantoche, permanecendo para além de sua compreensão.

Assim, segundo Jünger,

[...] justamente a certeza com a qual certos movimentos tipicamente progressistas levam a resultados que estão em oposição à sua própria intenção é que sugere a suposição de que aqui, como em todo o âmbito da vida, impõem-se menos as intenções do que os impulsos mais ocultos. O espírito se regala de muitos modos com o desprezo das marionetes de madeira do progresso - mas os finos arames que realizam seus movimentos são invisíveis. (JÜNGER, 2002, p. 191).

$\mathrm{Na}$ era tecnológica, todos somos expressões da Gestalt do soldado-trabalhador. Tudo permanece sob o domínio de um eterno ser que não pode ser explicado em termos humanos. O mundo forjado pela Gestalt do trabalhador, segundo Jünger, é a manifestação da vontade de poder. Tudo se submete às exigências da Gestalt que, por seu turno, esculpe todos os entes de modo que eles apareçam como matéria-prima no processo de mobilização total. A técnica não é, por isso, algo meramente técnico, mas é a forma mais perceptível da exigência niilista da manifestação da vontade de poder. Não é o homem que a tem, mas é a partir dela que a Gestalt o submete. Para o autor, a humanidade moderna está acorrentada pela Gestalt tecnológica. Jünger prevê que a Gestalt do trabalhador estava a encarrilhar a humanidade no modelo do soldado-trabalhador compelido a mobilizar a terra para a fundição industrial no nível planetário.

Jünger mostra-se pessimista quanto ao futuro da humanidade; para ele, não haveria modos de a humanidade escapar de ser cunhada pela Gestalt. Ele defende que o caminho face às investidas tecnológicas é a aceitação. No encerramento do texto $O$ trabalhador, ele diz: "aqui estamos para participar e para servir: tal é a tarefa que de nós se espera" (JÜNGER, 2000, p. 322).

A pretensão do domínio planetário é o símbolo da Gestalt. O mundo tende a assemelhar-se a uma monstruosa fundição, conforme diz Jünger em $O$ trabalhador, em que o motor não é o senhor, mas o símbolo de nosso tempo, a imagem de um poder que submete tudo às suas exigências. Os seus meios têm caráter provisório, oficinal e de uso temporário. Não há estabilidade de meios, nada é estável para além das curvas de produção ascendentes.

Esse domínio universal da vontade de poder manifesta nesse universo técnico, para que seja universalmente consumado, o engajamento de tudo e de todos. Para explicar tal 
necessidade, Jünger faz referência ao que ele chama de mobilização total. Com esse conceito, pretende descrever o processo globalizante da tecnologia moderna.

Para Jünger, o sentido do ser na atualidade é o da mobilização total do ente em seu todo, cujo expoente do qual decorre é a figura do trabalhador, que tende a objetificar incondicionalmente tudo o que está presente. "A técnica é o modo como a figura do trabalhador mobiliza o mundo.” (JÜNGER, apud HEIDEGGER, 1969, p. 29). A ação da mobilização total "é consumada por ela mesma mais do que por nós. É a expressão da reivindicação misteriosa e compulsória à qual nos submete essa vida da época das massas e das máquinas" (JÜNGER, 2002, p. 198). A vida de cada um torna-se uma vida de servidor (trabalhador), funcionário da técnica.

A era do trabalhador caracteriza-se pela crescente conversão da vida em energia. Modos e métodos de armação $^{11}$ já estão moldados à mobilização total e constantemente à disposição da Gestalt do trabalhador. A total mobilização é a medida do pensamento que organiza e que desempenha um papel exigente, na qual máquina e homem ${ }^{12}$ revelam-se instrumentos secundários, através dos quais ela se manifesta ${ }^{13}$. O mundo que é forjado pelo trabalho do trabalhador é a manifestação da vontade de poder cunhada pela Gestalt e operacionalizada pela mobilização total.

Essa mobilização total realiza a tarefa de desocultar energias e transformá-las em energia potencial disponível. Todos os entes aparecem, então, como matérias-primas no processo de mobilização. Tudo fora reduzido à mesma situação indiferenciada de matériaprima para a produção industrial. Nada passa a existir que não possa ser compreendido em sua funcionalidade ou em sua disponibilidade. "A rede elétrica da vida moderna, amplamente ramificada e cheia de dutos, é canalizada por meio de uma única chave na caixa de luz, para a corrente da energia bélica." (JÜNGER, 2002, p. 196). A Gestalt do trabalhador mobiliza o mundo enquanto reserva sem distinção. E, nós, homens, nos tornamos expressões vivas da Gestalt do soldado-trabalhador, como que funcionários dedicados a esse processo furioso.

\footnotetext{
${ }^{11}$ Armação (Rüstung) como o fenômeno mais imediatamente perceptível da mobilização total. Não apenas sob o prisma bélico, mas no sentido de estrutura do mundo sob o processo de mobilização total.

12 “A culpa pelo que se passa na Europa e na Alemanha começa a deixar de ser atribuída a indivíduos ou a um movimento político, mas a uma força planetária impessoal, a vontade de poder, que pensava estar além da responsabilidade ou do controle de cada um. Essa força tinha traduzido uma forma nova e infeliz de natureza humana: 'o trabalhador', considerado como orientado pela tecnologia e pela subjetividade de domínio universal." (FLEIG, 2005, p. 77-78).

13 “A racionalidade que está em ação na tecnologia moderna é meramente um meio impeditivo para um fim inerentemente não racional: produção pela produção.” (ZIMMERMAN, 2001, p. 119).
} 
Para quem pensa que o lado técnico da mobilização é o decisivo, Jünger diz que o pressuposto de toda técnica reside em sua essência, que não tem nada de técnico ou mecânico. A essência da técnica é o desvelamento de todos os entes como reservas disponíveis para realçarem a pura vontade de poder. O pressuposto de toda a técnica de Jünger trata como prontidão para a mobilização. É o que dá tal amplitude aos avanços tecnológicos. Prontidão que faz vibrar até a última centelha de vida e que arrasta todos os esforços nos quais se imprime a falta de finalidade, caracterizada na produção pela produção ou, mesmo, no querer pelo querer.

\section{O CONCEITO DE TÉCNICA DE HEIDEGGER APOIADO NO PENSAMENTO DE JÜNGER}

É possível encontrarmos, na compreensão acerca da técnica de Heidegger, formulações ou propriamente indicações da presença do pensamento de Ernest Jünger.

Heidegger fascinou-se pelos relatos de Jünger em como a experiência da frente de combate poderia transformar os homens em indivíduos corajosos, determinados e implacáveis e por sua analogia à guerra como figura de um tempo do progresso que se mostra enigmático e que "nenhuma técnica de cálculo prognóstico é capaz de dominar" (JÜNGER, 2002, p. 214), pois ela é apenas uma manifestação empírica de um espetáculo terrível, mas sublime que representa o processo globalizante da tecnologia moderna cunhada pela Gestalt do trabalhador.

No entanto, Heidegger divergiria de Jünger quanto à visão de futuro e destino da humanidade, bem como acreditava ser insuficiente a sua leitura acerca do pensamento de Nietzsche. Enquanto para Jünger urgia à humanidade submeter-se à inevitabilidade do que estava perante ela, Heidegger ansiava por um ultrapassamento essencial à era tecnológica.

Inicialmente, imaginou que o nacional-socialismo poderia ser essa alternativa ${ }^{14}$ ao mundo visionado por Jünger e, posteriormente, a partir de suas leituras de Hölderlin, passa a acreditar no poder da arte em dar voz ao acontecimento do ser e, em especial, através da poesia. Heidegger foi atraído pela crítica de Jünger e desmotivado pela sua visão de futuro.

O imaginário de Jünger nasce de suas experiências pessoais com acontecimentos extraordinários. Ele é levado pelo impulso de transformar a humanidade numa construção orgânica a serviço da vontade de poder, a traçar uma visão trágica e pessimista do futuro. Para

\footnotetext{
${ }^{14}$ Não é o objetivo deste artigo discutir a posição ou a possível aproximação de Heidegger em relação ao nacional-socialismo.
} 
ele não havia modos de a humanidade escapar de ser cunhada pela Gestalt. A aceitação e a submissão ao inexorável processo de industrialização total, e só ela, poderia dar significado a tal processo, assim como, do mesmo modo, a submissão ao gigantesco processo da guerra deu significado à Primeira Guerra Mundial e a soldados como ele próprio. Para ele, o homem transformado em soldado-trabalhador vê, nesse espetáculo horrível, o processo oculto da vontade de poder que mobiliza, de forma total, tudo em vista de seu fim. Segundo Jünger, depois de a humanidade ter-se rendido à Gestalt do trabalhador, teria lugar um período de destruição e produção de um mundo tecnologicamente perfeito, mas que daria margem a uma nova vontade de poder, que tornaria presentes todos os entes apenas como reserva e disponíveis, num círculo irremediável e no qual estaríamos encarcerados. "É bem seguro que apenas uma força de tipo cultural poderia chegar à audácia de estender ao infinito a perspectiva da finalidade utilitária" (JÜNGER, 2002, p. 192), na qual se imprime a marca da falta de finalidade; para ele, "se alguém perguntasse a alguns daqueles jovens por que ele se deslocava no campo de batalha, certamente poderia contar com uma resposta pouco clara" (JÜNGER, 2002, p. 207).

Heidegger, igualmente, percebe o abandono da humanidade pelo ser, mas ressalta que isso não era algo negativo, mas apenas representava o estágio final de um processo histórico sobre o qual a humanidade é capaz de exercer total controle. Quanto a isso, Heidegger não era inimigo da tecnologia, e nem via nela um elemento demoníaco. Essa época representaria uma época simultaneamente perigosa e cheia de esperanças, mas que precisaria ser compreendida a partir da compreensão de sua essência.

Jünger contribui para a formulação da ideia de Heidegger de que a história da humanidade está enlaçada à vontade de poder, e de que a história do mundo é constituída por manifestações da referida vontade. O ser, na história ocidental, assemelhar-se-ia à coisa como qualidade do ser. A metafísica concentrou-se naquilo que determinaria o horizonte de mostração do ser, o ente. No entanto, Jünger, segundo Heidegger, não teria sido capaz de pensar fora dos limites da própria metafísica, pois teria faltado a ele a compreensão da diferença ontológica, pois a Gestalt não é a causa, mas o princípio que ilumina os entes no seu aparecer como reserva disponível para a total mobilização. Heidegger, em 1939/1940, em seu comentário a Der Arbeiter de Jünger, afirma que a posição fundamental de Jünger é em 
"muitos pontos insuficiente e com fundamentos não examinados e sem base" (HEIDEGGER, 2004, p. 213).

Para Heidegger, o fascínio da humanidade tecnológica pelas explicações de causa e efeito demonstra que as pessoas são, agora, regidas pela Gestalt da Ratio - racionalidade calculadora - que impõe que tudo deva dar uma razão para si mesmo, perante o tribunal do sujeito-de-si-próprio. No entanto, a Ratio não é absolutamente um juiz justo, pois,

[...] sem vacilar ela rejeita tudo o que não se lhe adapta e a empurra para o presumido pântano do irracional, delimitado, de resto, pela própria razão. A razão e sua representação constituem apenas uma maneira de pensar e de nenhum modo são determinadas por si mesmas, mas por aquilo que ordenou o pensamento a pensar à maneira da Ratio. (HEIDEGGER, 1969, p. 16-17).

Heidegger acredita que a Gestalt de Jünger não consegue ultrapassar a concepção metafísica tradicional do ser, pois a própria humanidade trabalhadora seria a responsável por assumir ou dar origem a si mesma enquanto Gestalt, ou seja, como se ela tivesse se transformado em doadora de significação e outorgante de fundamento para as próprias coisas $^{15}$. O que Heidegger diz é que a própria humanidade foi transformada em trabalhador. Para fazer referência à era da técnica, deve-se compreender a Gestalt do trabalhador como sendo a fase final da história do ser $^{16}$, orientada sob a forma tradicional (descrita como planificada ou moldada permanentemente à cunhagem das coisas). Gestalt do trabalhador significa um constrangimento do ser dos entes, incluindo a própria humanidade como reserva disponível.

Por mais divergências que encontremos entre o conceito de técnica de Heidegger e o de Jünger, é possível afirmar que o pensamento de Jünger está presente no de Heidegger e colabora na sua formação. Essa proximidade é perceptível na seguinte analogia: para Jünger, a Gestalt do trabalhador compele a humanidade a mobilizar-se a si própria e ao planeta como reserva disponível para favorecer o projeto tecnológico de controle total e, para Heidegger, a humanidade, na era tecnológica, é desafiada a avançar pela Gestalt a tratar-se a si mesma e a todos os outros ser-dos-entes como reserva disponível para a mobilização.

\footnotetext{
${ }^{15}$ Heidegger aponta que a leitura de Jünger acerca da vontade de poder não foi capaz de revelar o que ela própria representa, ou seja, o ponto máximo da subjetividade.

${ }^{16}$ Heidegger fala da "história do ser" e Jünger da "história da vontade de poder".
} 
Heidegger concebe o conceito de vontade de poder como o ser esmagador, o ser presente do ente que empurra a humanidade a levar o ser a um paradouro, a limitar e a confinar o ser, de modo que os entes manifestem-se de determinada maneira. O ser ou a vontade de poder assumem múltiplas facetas em diferentes épocas. A humanidade é moldada para agir em conformidade com os imperativos imanentes do modo do ser que governa a era do trabalhador. Acorrentada pela Gestalt tecnológica, a humanidade não presta atenção no acontecimento originário ${ }^{17}$. Uma humanidade agarrada à tecnologia como instrumento para alcançar a segurança e a felicidade não permite uma abertura autêntica à verdade, o que possibilitaria ultrapassar o perigo na era da técnica.

$\mathrm{Na}$ época em que o trabalhador-soldado está a configurar (moldar) a estrutura básica do fazer/criar humano, o trabalho atinge a metafísica da objetificação incondicional de tudo o que é presente a partir da vontade de querer. A humanidade subordina-se à susceptibilidade da existência como presente, controlável e disponível. "Trata-se de algo exigido pelo imperar do Gestell, que a requeribilidade da natureza exige enquanto subsistência: que a natureza se anuncie de algum modo asseverado, calculado e permaneça possível de ser requerida." (HEIDEGGER, 1997, p. 71). Então:

[...] o madeireiro que percorre do mesmo modo, tal como o seu avô, os caminhos da floresta, é hoje requerido pela indústria madeireira, saiba ele disso ou não. Ele é requerido pela exigência (forçado a subordinar-se à susceptibilidade) de celulose que, por sua vez, é desafiada pela necessidade de papel, que é fornecido para os jornais e para as revistas ilustradas. Estes, por seu turno, dispõem da opinião pública para que esta devore o que é impresso e esteja disponível para um arranjo opinativo e encomendado. (HEIDEGGER, 1997, p. 63).

No entanto, apesar de a realização dessa configuração do trabalho passar pela atividade humana, o homem participa dela apenas como um modo do realizar o ser, no sentido de que ele próprio é convocado pelo ser. Isso faz com que os homens, então, desviem o olhar, em vista da segurança do ser das coisas, almejando saber como obter o controle sobre os entes dentro de um mundo histórico. No entanto, ele próprio faz parte do controlado, tornando-se controlável.

\footnotetext{
${ }^{17}$ Heidegger vai denominá-lo de Ereignis. Palavra que só se permite pensar a partir da experiência de um momento singular: o acontecimento-apropriador. Essa inversão, em busca da raiz, do originário, caracteriza o incessante movimento regressivo característico do próprio estar a caminho, até alcançar o pensamento do acontecimento-apropriação (Ereignis). O pensamento do Ereignis não significa o fechamento do caminho, mas antes a abertura do âmbito mais adequado para que se dê a mostração do ser enquanto tal.
} 
Para Heidegger, o que ocorre em Jünger é uma real e verdadeira experiência metafísica no momento em que ele percebe, na figura do soldado-trabalhador, o desamparo total, a experiência viva do nada, na frente de batalha. "Jünger não tinha em sua mochila o livro que trazia na capa 'Nietzsche, A vontade de poder', - mas é pelo fogo e pelo sangue, pela morte e pelo trabalho, pelo silêncio e pelas tempestades da batalha armada como manifestação da vontade de poder que ele foi tocado." (HEIDEGGER, 2004, p. 218).

Se o pensamento de Ernest Jünger encontra em Nietzsche suas raízes mais próprias não é, explica Heidegger, em razão de uma afiliação intelectual ou doutrinária, mas sim, porque Jünger realizou em sua própria carne a experiência fundamental da vontade de poder no que ela tem de mais efetivo: a prova tanto física como metafísica das "tempestades de aço", tais como se abateram no coração das trincheiras durante a Primeira Guerra Mundial (ARJAKOVSKY, 2007, p. 1250).

No entanto, Jünger não teria tido sucesso em sua compreensão a respeito de Nietzsche. Ele não teria compreendido o real significado da vontade de poder como sendo, segundo Heidegger, o ponto máximo e final da metafísica da subjetividade. Inclusive, o próprio título do terceiro capítulo de Zu Ernest Jünger, no qual são lançados esboços de sua crítica, se lê: “a cegueira de Ernest Jünger e sua limitação radical decorrente do enraizamento na metafísica de Nietzsche" (HEIDEGGER, 2004, p. 11).

Após situar a clara relação de dependência de Jünger para com Nietzsche, Heidegger pondera que a verdadeira questão não é conferir as citações textuais de ambos os autores, examinar

O que há de efetivo no sentido da vontade de poder e de nossa relação com ela. E, a partir disso, saber se conhecemos essa efetividade de maneira suficiente e se, a partir desse acontecimento, nós preparamos juntos às decisões críticas que se impõem em vista de sua superação - ou, então, se nós persistimos uma vez mais em mascarar esta efetividade. (HEIDEGGER, 2004a, p. 220).

O que Heidegger faz é reconhecer que em Jünger se dá uma experiência do ser na forma extrema da vontade de poder, ao ser tocado pelos efeitos desse poder planetário, presente na guerra generalizada, ou seja, mundial. Aquilo que é afirmado por Jünger é precisamente o que é criticado por Heidegger, ou seja, que em Jünger trata-se de um elogio da vontade de poder, calcada na extrema realização da subjetividade moderna, que não considera a dimensão da diferença ontológica. 
Heidegger reconhece que Jünger foi um dos primeiros a descrever o desencadeamento infinito de uma vontade de poder, viabilizada pelos avanços da técnica moderna (aperfeiçoamento das armas, motorização dos meios de transporte terrestre, marítimo e aéreo, avanços nos meios de comunicação, etc.), e que não tem como único fim o puro poder. A mobilização total da técnica moderna, como acontecimento metafísico próprio do acabamento da metafísica, é o que Heidegger coloca em questão em seu confronto com Jünger.

A vontade de dominar é também expressão do desocultamento técnico do mundo. Heidegger volta-se, de forma crítica, contra a vontade moderna, e apresenta-a como o ponto de partida da imposição e da dominação. A partir da segunda metade dos anos 30, Heidegger trabalha no plano metafísico o mero querer, a vontade vazia que conhece somente um conteúdo: o poder. Este, por sua vez, é indispensável para o desocultamento técnico. O mero poder, longe de representar novos e outros valores, cobre somente o vácuo da vontade e camufla-se como saída, mas é, na verdade, uma outra forma do esquecimento do ser, uma forma marcada pelo desocultamento técnico dele.

\section{REFERÊNCIAS}

DUARTE, André. Heidegger, a Essência da Técnica e as Fábricas da Morte: Notas sobre uma questão controversa. In: SOUZA, Ricardo Timm; OLIVEIRA, Nythamar Fernandes de (org.). Fenomenologia hoje: existência, ser e sentido no alvorecer do século XXI. Porto Alegre: EDIPUCRS, 2001. p. 37-65.

FLEIG, Mário. Os impasses da crítica heideggeriana à ciência moderna e à técnica. In: REGNER, Anna Carolina; ROHDEN Luis (org.). A filosofia e a ciência redesenham horizontes. São Leopoldo, RS: UNISINOS, 2005. p. 73-93.

HEIDEGGER, Martin. A questão da técnica. In: LEÃO, Emmanuel Carneiro. Ensaios e Conferências. Petrópolis, RJ: Vozes, 2001. p. 11-38.

HEIDEGGER, Martin. A questão da técnica. In: WERLE, Marco Aurélio. Cadernos de Tradução, n. 2, Departamento de Filosofia da USP, 1997. p. 40-93.

HEIDEGGER, Martin. Carta-resposta de Heidegger ao professor da Universidade de Tóquio, dr. Takehiko Kojima. In: STEIN, Ernildo. Uma breve introdução à filosofia. Ijuí: Unijuí, 2002. p. 193-202.

HEIDEGGER, Martin. Sobre o problema do ser. Tradução de Ernildo Stein. São Paulo: Livraria Duas Cidades, 1969. 
HEIDEGGER, Martin. Um prefácio - Carta de Heidegger ao Pe. Willian Richardson. Revista da Unisinos, São Leopoldo, RS, v. 5, n 8, p 49- 62, 2004b.

HEIDEGGER, Martin. Zu Ernest Jünger. Frankfurt: V. Klostermann, 2004a.

JÜNGER, Ernst. O trabalhador: domínio e figura. Introdução, tradução e notas Alexandre Franco de Sá; prefácio Nuno Rogeiro. Lisboa: Hugin, 2000.

JÜNGER, Ernest. A mobilização total. Natureza Humana: Revista Internacional de Filosofia e Prática Psicoterápicas do Programa de Estudos Pós-Graduados em Psicologia Clínica da PUC-SP, São Paulo, v. 1, n. 4, p.189-216, 2002. Disponível em:

http://pepsic.bvsalud.org/pdf/nh/v4n1/v4n1a06.pdf . Acesso em: 24 set. 2019.

SAFRANSKI, Rüdiger. Heidegger: um mestre da Alemanha entre o bem e o mal. Tradução Lya Luft. São Paulo: Geração, 2000.

STEIN, Ernildo. Compreensão e finitude: estrutura e movimento da interrogação heideggeriana. Ijuí: UNIJUÍ, 2001.

THIELE, Leslie Paul. Martin Heidegger e a política pós-moderna: meditações sobre o tempo. Lisboa: Instituto Piaget, 1995.

ZIMMERMAN, Michael E. Confronto de Heidegger com a modernidade. Lisboa: Instituto Piaget, 2001. 